\title{
Disasters, Human Rights and Vulnerability: Reflections from the Experiences of Older Persons in Post-Quake Canterbury
}

\author{
Natalie Baird*
}

International experience has shown that pre-existing vulnerabilities and patterns of discrimination are usually exacerbated in times of disasters. ${ }^{1}$ This appears to be the case no matter the level of development of the country concerned: '[e]ven in developed countries, disasters have a knack of finding the poor and vulnerable.' ${ }^{2}$ Thus, the concept of vulnerability appears highly relevant and potentially useful to international disaster law. However, much like international disaster law itself, the precise parameters of the concept of vulnerability are not yet well-defined. Similarly, the exact place of vulnerability in both international human rights law and international disaster law is imprecise. Although vulnerability is regularly referenced in the wider international human rights discourse, and increasingly used by human rights decisionmaking bodies, it does not yet have a firm footing within international human rights law. Similarly, in international disaster law, although the International Law Commission makes numerous references to vulnerability in its 2016 Draft Articles on the Protection of Persons in the Event of Disasters, the exact way in which vulnerability is to be applied in practice is unclear.

This article explores the relationship between disasters, human rights and vulnerability using a case study of the experiences of older persons in postquake Canterbury, New Zealand. The precise contours of the relationship between disasters, human rights and vulnerability are still developing and

* Associate Professor, School of Law, University of Canterbury. I am grateful to Natacha Wisstt for her research assistance for this article and to the anonymous reviewers for their very helpful comments and insights. All errors and omissions are my own. I also note that as this article was being finalised, the world was grappling with how to respond to the Covid-19 pandemic. This pandemic has had and continues to have a disproportionate impact on older persons. This has brought some of the observations in this article into sharper relief although time and space preclude consideration of this wider context.

1 IAsC Operational Guidelines on the Protection of Persons in Situations of Natural Disasters (2011), 2.

2 Charles W Gould, 'The Right to Housing Recovery after Natural Disasters', (2009) 22 Harvard Human Rights Journal, 169, 169 . 
so the article aims to consider these intersections through the window of the Canterbury case study. The intention is to connect the theory of vulnerability with the practice of a particular disaster and reflect on whether this offers any insights for development of the concept in international human rights law and international disaster law.

Part 2 of this article explores the linkages, overlaps and disconnects between the concept of vulnerability, the international human rights framework and international disaster law. Part 3 details three snapshots of the experience of older persons in Canterbury following the 2010-2011 earthquakes. Drawing on Parts 2 and 3, Part 4 then offers some reflections on the concept of vulnerability in light of the Canterbury experience. Ultimately, this article concludes that despite its complexities and uncertainties, vulnerability is a useful concept for better protecting the rights of individuals and groups in the disaster context. Disaster Law

This part of the article first considers the concept of vulnerability simpliciter and sets out the core parameters of vulnerability theory. It then looks at how international human rights law and discourse uses the notion of vulnerability, and then does the same for international disaster law.

\subsection{The Concept of Vulnerability}

Vulnerability has been described as 'a concept fraught with paradox' with scholars across various disciplines referring to it as 'confusing, complex, vague, [and] ambiguous. ${ }^{3}$ Many different disciplines have engaged with the concept of vulnerability, with (bio)ethics and law in particular spawning an extensive vulnerability literature. ${ }^{4}$ While there is much about vulnerability that is contested and critiqued, there appears to be agreement at least on the point that the term "vulnerability" or "vulnerable" most often refers to certain individuals or groups who 'should be the recipients of extra care and attention. ${ }^{5}$

In the disaster context, vulnerability has been defined as 'the characteristics of a person or group and their situation that influence their capacity to

3 Lourdes Peroni and Alexandra Timmer, 'Vulnerable groups: The promise of an emerging concept in European Human Rights Convention law', (2013) 11/4 International Journal of Constitutional Law, 1056, 1058.

4 Ibid.

5 Alexander H E Morawa, 'Vulnerability as a Concept of International Human Rights Law', (2003) 6/2 Journal of International Relations and Development, 139, 139. 
anticipate, cope with, resist and recover from the impact of a hazard. ${ }^{6}$ The causes of vulnerability of a particular individual or group can be multiple and compounding. Vulnerable groups will also typically experience 'discrimination, social exclusion, stigmatization, and deprivation of protections and entitlements on an ongoing basis. ${ }^{7}$ Beyond these basic elements though, there is little agreement as to what the concept entails or what it requires from state actors in different contexts.

\subsection{Vulnerability Theory}

Martha Fineman is one of the leading scholars on the notion of vulnerability. ${ }^{8}$ She considers that vulnerability is useful to recognise the hidden biases that are interwoven into our legal practices and systems. She posits that a focus on equality alone is not enough to truly tackle historical and social inequalities. Instead, the concept of vulnerability dives deeper and links human experience with wider context by considering other factors such as development, governance and power inequalities. ${ }^{9}$ Poverty and extreme poverty are increasingly being recognised as a significant cause of vulnerability. ${ }^{10}$ Fineman argues that 'if our bodily fragility, material needs, and the possibility of messy dependency (...) cannot be ignored in life, how can they be absent in our theories about equality, society, politics, and law?'11 She suggests that vulnerability theory must also incorporate considerations of dependency - an inherent element of the human condition that significantly impacts the human experience. She points out that the experience of vulnerability is 'greatly influenced by the quality and quantity of resources we possess or can command. ${ }^{12}$ Using vulnerability as an analytical tool involves 'exploring how societal or institutional arrangements originate, sustain, and reinforce vulnerabilities'.13

$6 \quad$ Ben Wisner et al, At Risk: Natural Hazards, People's Vulnerability and Disasters (Routledge 2004) 11.

7 Audrey R Chapman and Benjamin Carbonetti, 'Human Rights Protections for Vulnerable and Disadvantaged Groups: The Contributions of the UN Committee on Economic, Social and Cultural Rights', (2011) 33 Human Rights Quarterly, 682, 683.

8 Martha Albertson Fineman, 'The Vulnerable Subject and the Responsive State', (2010)6o Emory Law Journal, 251.

9 Mariangela Bizzarri, 'Protection of Vulnerable Groups in Natural and Man-Made Disasters' in A de Guttry, M Gestri and G Venturini (eds), International Disaster Response Law (TMC Asser Press 2012) 386.

$10 \quad$ Chapman and Carbonetti $\left(\mathrm{n}_{7}\right) 684$.

11 Fineman (n 8) 263.

12 Martha Albertson Fineman, 'The Vulnerable Subject: Anchoring Equality in the Human Condition', (2008-2009) 20 Yale Journal of Law and Feminism, 1, 10.

13 Peroni and Timmer (n 3$) 1059$. 
Fineman's approach in some ways complements the "human development" or "capabilities" approach developed originally by Amartya Sen and expanded by Martha Nussbaum and others. Sen developed the capabilities approach to provide new perspectives on welfare economics. ${ }^{14}$ The approach challenges the assumption that human well-being is based on economic success alone. Instead it allows society and individuals to decide what is or is not a valuable life. It does this by asking 'What are people actually able to do and to be? What real opportunities are available to them?' ${ }^{15}$ It critiques the dominant model of society as a social contract and instead recommends a society based on the idea of fostering human capabilities. ${ }^{16}$ The capabilities approach thus aims at the development of an environment suitable for human flourishing. It recognises diversity in the human experience as 'people may need different quantities of resources if they are to come up to the same level of ability to choose and act, particularly if they begin from different social positions. ${ }^{17}$ Importantly, the capabilities approach identifies the flaw in the presumption that we are (or ought to be) autonomous beings because this 'ignores the reality of the variable levels of dependency over our life cycle, as well as the risks inherent to our condition as human beings: illness, accident and old age. ${ }^{18}$

Drawing also on this idea of variable levels of dependency over the life cycle, Fineman argues that vulnerability is similarly a 'universal, inevitable, enduring aspect of the human condition'19 and so can be experienced by anyone and everyone, even if they do not belong to a group typically regarded as vulnerable. This means that neither privilege nor disadvantage automatically flow from identity. Instead, within the various systems for conferral of benefits such as education, health and wealth, individuals are often positioned differently from one another so that 'some are more privileged, while others are relatively disadvantaged'. 20

While the argument that vulnerability is a constant aspect of the human condition and is universal to us all has appeal, others argue for a more particular approach. For example, Cooper suggests that some groups and identities

\footnotetext{
14 Amartya Sen, Commodities and Capabilities (Oup 1987).

15 Martha C Nussbaum, Creating Capabilities: The Human Development Approach (Harvard University Press 2011) $\mathrm{x}$.

16 Martha C Nussbaum, 'Care, Dependency and Social Justice: A Challenge to Conventional Ideas of the Social Contract' in Peter Lloyd-Sherlock (ed), Living Longer: Ageing, Development and Social Protection (Zed Books 2004) 277.

17 Nussbaum (n 15) 186.

18 Eugenia Caracciolo di Torella and Annick Masselot, Caring Responsibilities in European Law and Policy: Who Cares? (Routledge 2020) 42.

19 Fineman (n 12$) 8$.

$20 \quad$ Ibid., 15 .
} 
are inherently vulnerable while others are inherently privileged. ${ }^{21} \mathrm{He}$ argues that 'the problem with subsuming identities under vulnerability theory's principles of complexity and particularity is that we are not all vulnerable in the same ways or even to the same degrees. ${ }^{22}$ Cooper takes issue with Fineman's suggestion that vulnerability is the culmination of economic and institutional factors that can compound an individual's vulnerability rather than multiple identities of the self. ${ }^{23} \mathrm{He}$ argues instead that incorporating considerations of privilege into vulnerability analysis will mean that vulnerability theory will 'be able to explain how systems of power both benefit some identities and make others more vulnerable.' ${ }^{24}$

This universal/particular debate and the place of identity remain core areas of disagreement in the theory of vulnerability. However, it is clear that vulnerability depends - to a greater or lesser degree - on a combination of an individual's identity(ies), degree of privilege, relative experience of dependency and disadvantage, as well as broader structural factors such as development, governance, power inequalities, poverty and marginalisation.

\subsection{Vulnerability in International Human Rights Law}

Although there are no explicit references to vulnerability in the core international human rights treaties, the very purpose of human rights is to ensure that the human rights of everyone, no matter their vulnerability, are protected and respected. Despite the lack of direct references, the terminology of vulnerability is regularly referenced in the wider international human rights discourse. However, there is no single approach to the definition of vulnerability in international human rights law, but instead 'a vast practice of identifying the particularly vulnerable for very limited purposes'. ${ }^{25}$ Usages of vulnerability are ad hoc rather than systematic. Expressing this more positively, it might be said that its usage is often intuitive - it is invoked in the same way that the concept of "dignity" is invoked. ${ }^{26}$

One area lacking clarity is whether vulnerability is simply a label for especially disadvantaged and marginalised groups, or whether it is a more far-reaching concept. Consensus appears to be emerging that vulnerability is something more than "just" a label. In other words, vulnerability does more

\footnotetext{
21 Frank Rudy Cooper, 'Always Already Suspect: Revising Vulnerability Theory', (2015) 93/5 Common Law Review, 1339.

22 Ibid., 1356.

23 Fineman (n 8) 268.

24 Cooper (n 21) 1373.

25 Morawa (n 5$) 15$ o.

26 I am grateful to one of the anonymous reviewers for this insight.
} 
than simply describe the predicament of those who are vulnerable, it has legal ramifications. ${ }^{27}$ In the context of economic, social and cultural rights, Chapman and Carbonetti have suggested that states have three obligations they are obliged to monitor the status of vulnerable groups, protect their basic social and economic rights even in times of austerity and stringency, and accord them priority in the realisation of rights. ${ }^{28}$ Vulnerability provides an opportunity to 'move closer to a more robust idea of equality' by allowing decision makers to 'address different aspects of inequality in a more substantive manner. 29

Vulnerability is closely linked to the core human rights principle of nondiscrimination. The principle of non-discrimination is typically concerned with ensuring that vulnerable individuals and groups are accorded their rights without discrimination. Thus, some of the prohibited grounds of discrimination (race, ethnicity, age, gender, disability) also identify population groups especially susceptible to vulnerability. Similarly, some of the core human rights treaties protect the rights of particularly vulnerable groups including racial or ethnic minorities (CERD), women (CEDAW), children (CRC), people with disabilities (CRPD) and migrant workers (ICRMW). However, the precise intersections between vulnerability and discrimination are not clear. In particular, it is not clear whether vulnerability is a cause of discriminatory treatment, whether it is a result of discriminatory treatment, or whether it can be both.

As with intersectional discrimination, the vulnerability of individuals may also be 'compounded and layered'. ${ }^{30}$ For example, individuals within the same broad group of older persons do not necessarily experience the same level of vulnerability in the same way. Particular individuals or sub-groups within a vulnerable group may experience multiple forms of vulnerability. Thus, an older person could also be experiencing severe poverty or suffering from a serious health issue. These compounding or multiple vulnerability factors can result in weaker human rights protection, or more serious violations of human rights. Therefore, as is the case with discrimination, a holistic approach to vulnerability is essential to grasp the multifaceted set of interrelationships that illustrate how elaborate vulnerability can be. ${ }^{31}$

\footnotetext{
27 Ingrid Nifosi-Sutton, 'A Human Rights-Based Vulnerability Paradigm: Lessons from the case of displaced women in post-quake Haiti' in Flavia Zorzi Giustinani et al (eds), Routledge Handbook of Human Rights and Disasters (Routledge, 2018), 281.

28 Chapman and Carbonetti (n 7) 693.

29 Peroni and Timmer (n 3$) 1074$.

$30 \quad$ Nifosi-Sutton (n 27) 28 o.

$31 \quad$ Bizzarri (n 9) 388.
} 
Amongst human rights institutions, the European Court of Human Rights has been especially active in engaging with the concept of vulnerability. ${ }^{32}$ Although the Court clearly ascribes some meaning to the concept, it has not yet crystallised the core elements of a vulnerability approach. It has instead limited itself to considering vulnerability as flowing from group-based historical stigmatisation and discrimination. ${ }^{33}$ Groups which have benefited from this analysis include persons living with HIV/AIDS, people with mental health issues, asylum seekers and Roma. ${ }^{34}$

The Committee on Economic, Social and Cultural Rights (CESCR) under ICESCR is another body which regularly uses the terminology of vulnerability. It typically uses the formula 'vulnerable or marginalized and disadvantaged groups,' ${ }^{35}$ and references to vulnerability in its documentation have increased in recent years. ${ }^{36}$ CESCR has even identified victims of disasters as a vulnerable group. ${ }^{37}$ Writing in 2011, Chapman and Carbonetti concluded that CESCR did not provide a clear-cut conception or definition of vulnerability. ${ }^{38}$ Instead, CESCR took a "two-pronged approach" to identifying vulnerability, with the first prong focused on an individual's membership of a vulnerable group, and the second focused on the human rights issues which were either a cause or effect of vulnerability. ${ }^{39}$ CESCR's approach to vulnerable groups has since developed so that it now emphasises the lack of effective legal protection characterising the situation of those identified as vulnerable, rather than simply describing individuals as vulnerable because of particular characteristics. ${ }^{40}$ However, CESCR still tends to address vulnerability as an attribute of groups or communities rather than as a universal concept which can affect any and all individuals. ${ }^{41}$ CESCR's articulation therefore reflects law's traditional approach by considering certain situations or personal categories as deserving special attention and protection given past or ongoing prejudice and disadvantage. ${ }^{42}$

32 Peroni and Timmer ( $\left.\mathrm{n}_{3}\right)$.

33 Michael O'Boyle, "The notion of 'vulnerable groups' in the case law of the European Court of Human Rights" (Report presented at the Conference on the Constitutional Protection of Vulnerable Groups: A Judicial dialogue, Santiago, Chile, 4-5 December 2015), at 2.

Peroni and Timmer (n 3$)$.

35 Nifosi-Sutton (n 27) 279 .

36 Chapman and Carbonetti (n 7) 710 and 721.

37 CESCR, 'General Comment No 4: The Right to Adequate Housing' (1991), para. 8(e).

38 Chapman and Carbonetti (n 7 ).

39 Ibid., 721.

$40 \quad$ Nifosi-Sutton (n 27) 284.

41 Chapman and Carbonetti (n 7$) 725$.

42 Therese O'Donnell, 'Vulnerability and the International Law Commission's Draft articles on the Protection of Persons in the Event of Disasters', (2019) 68 International and Comparative Law Quarterly, 573, 586. 
The UN Human Rights Council's Independent Expert on the enjoyment of all human rights by older persons has taken a comprehensive approach to vulnerability in the disaster context. She has identified that the vulnerabilities of older persons in emergency contexts may be intrinsic (such as poor health, disability or frailty), extrinsic (due to low income, low degree of literacy or the remoteness of the place of residence) or due to systemic factors (such as lack of disaggregated data, or failure to assess needs correctly or to monitor the effectiveness of assistance provided). ${ }^{43}$ She also recognises a wide range of potentially compounding factors 'that accumulate during a lifetime' including gender, race, education level, income, health status, disability and access to justice with the result that different subgroups of older persons may experience different levels of vulnerability. ${ }^{44}$ Vulnerability may also be social, with 'social connectedness' in an emergency situation being a key factor in determining the health or wellbeing of an older person. ${ }^{45}$

The CEDAW Committee has also engaged with the notion of vulnerability, including in the context of disasters. In its 2010 General Recommendation No. 27 on older women and protection of their human rights, it noted that '[c]limate change impacts differently on women, especially older women who, due to their physiological differences, physical ability, age and gender, as well as social norms and roles and an inequitable distribution of aid and resources relating to social hierarchies, are particularly disadvantaged in the face of natural disasters. ${ }^{46}$ In addition, older women's limited access to resources and decision-making processes increases their vulnerability to climate change. ${ }^{47}$ By the time of its 2018 General Recommendation No. 37 on the gender-related dimensions of disaster risk reduction in the context of climate change, the CEDAW Committee appeared to appreciate the deeper complexity of vulnerability. It noted that vulnerability was 'economically, socially and culturally constructed' and that '[t]he categorization of women and girls as passive "vulnerable groups" in need of protection from the impacts of disasters is a negative gender stereotype that fails to recognize the important contributions of women in the areas of disaster risk reduction, post-disaster management and climate

43 HR Council, 'Enjoyment of all human rights by older persons: Report of the Independent Expert on the enjoyment of all human rights by older persons' (4 July 2019) A/HRC/42/43, para. 24.

$44 \quad$ Ibid., paras. 25 and 82.

45 Ibid., para. 29.

46 CEDAW Committee, 'General Recommendation No. 27 on Older Women and Protection of their Human Rights' (16 December 2010) CEDAW/C/GC/27, para. 25.

Ibid. 
change mitigation and adaptation strategies. ${ }^{48}$ General Recommendation No. 37 also identified gradations of vulnerability with different groups of women more at risk than others - such as women heads of household and women who migrate..$^{49}$ Despite this appreciation of some of the nuances of vulnerability, discrimination and substantive equality, General Recommendation No. 37 has been critiqued for perpetuating problematic gender narratives and stereotypes including 'the implicit "victim narrative" that is solely assigned to women.'50 Even though the CEDAW Committee explicitly exhorts rejection of gender stereotypes, it fails to consistently adhere to this itself, with women's universal vulnerability assumed in many places in the General Recommendation. ${ }^{51}$

This misstep by the CEDAW Committee illustrates a danger of invoking vulnerability, i.e. it is potentially stigmatising given that being vulnerable is typically associated with powerlessness and weakness. ${ }^{52}$ Another concern is that it may result in victimisation of those who are vulnerable and corresponding paternalism from those in power. ${ }^{53}$ Paternalistic responses may in turn lead to exclusion of vulnerable groups from participation in and contribution to processes that affect them. A third concern is that the invocation of vulnerability may lead to essentialism by treating all disaster victims as the same and overlooking the diversity of individual group members or subgroups. ${ }^{54}$ Mitigating these risks requires using vulnerability as more than a mere adjectival label, by considering the particular reasons why a group or individual is vulnerable, ${ }^{55}$ identifying structural factors contributing to vulnerability and focussing on the corresponding state obligations.

Essentially the way in which the concept of vulnerability is currently used in international human rights law is to recognise that while everyone is entitled to have their human rights respected, protected and fulfilled, there are some groups and individuals who are more vulnerable than others and so require

48 CEDAW Committee, 'General Recommendation No. 37 on the Gender-related Dimensions of Disaster Risk Reduction in the Context of Climate Change' (13 March 2018) CEDAW/ C/G/37, paras. 6-7.

49 Ibid., paras. 4 and 75 .

50 Monika Mayrhofer, 'Gender (In)equality, Disaster and Human Rights - the CEDAw Committee and General Recommendation No. 37', (2019) 1 Yearbook of International Disaster Law, 233, 252.

$51 \quad$ Ibid., 253.

$5^{2} \quad$ Nifosi-Sutton (n 27) 284.

53 Peroni and Timmer (n 3 ) 1072-1073.

54 Ibid., 1071-1072.

55 V Flegar and E Iedema, "The Use of the "Vulnerability" Label by the Committee on the Elimination of Discrimination Against Women: Protecting or Stigmatizing Women and Girls in the Forced Migration Context?', (2019) Brill Open Law, 1, 40. 
specific attention. To date, international human rights law has however primarily relied on identifying especially vulnerable groups, rather than adopting Fineman's broader approach and recognising that all individuals may experience vulnerability. In addition, while vulnerability is now regularly referenced in various human rights fora, and there is a growing understanding of the complexity of the concept and that it leads to discrete obligations on states, vulnerability has not yet crystallised into an independent standalone concept or organising principle.

\subsection{Vulnerability in International Disaster Law}

As is the case with international human rights law, the concept of vulnerability is highly relevant to international disaster law. This is particularly so given that ' $[\mathrm{d}]$ isasters are now recognised as the product of the multiple interactions between hazards, vulnerabilities and people's coping capacity' ${ }^{56}$ Indeed, a succinct definition of "disaster" is that it is a natural hazard plus vulnerability. ${ }^{57}$ Disasters themselves do not discriminate against particularly vulnerable individuals and groups. However, it is well-established that the consequences are not the same for all those affected; 'rather they are often determined by discrimination patterns that pre-exist the hazard and undermine the ability of certain groups to resist, accommodate, and recover from it'.58 Given the importance of vulnerability to the experience of individuals and groups following a disaster, it is therefore necessary to examine how international disaster law uses the concept.

A logical starting point to consider how international disasterlaw approaches the question of vulnerability is to look at the International Law Commission's 2016 Draft Articles on the Protection of Persons in the Event of Disasters (the Draft Articles). The first point to observe is that, unlike other definitions of disaster which explicitly incorporate the idea of vulnerability, the Draft Articles do not. Instead, a more conservative definition is adopted - disaster is defined as 'a calamitous event or series of events resulting in widespread loss of life, great human suffering and distress, or large-scale material or environmental damage, thereby seriously disrupting the functioning of society. 59

\footnotetext{
$56 \quad$ Bizzarri (n 9) 383 .

57 Dug Cubie and Marlies Hesselman, 'Accountability for the Human Rights Implications of Natural Disasters: A Proposal for Systemic International Oversight', (2015) 33/1 Netherlands Quarterly of Human Rights, 9, 16.

$58 \quad$ Bizzarri (n 9) 389 .

59 International Law Commission, 'Draft articles on the protection of persons in the event of disasters' (2016) A/71/10, art. 3.
} 
Draft articles 4-6 are the most pertinent to human rights and vulnerability. Article 4 provides that the 'inherent dignity of the human person' is to be protected, and art. 5 that '[p]ersons affected by disasters are entitled to the respect for and protection of their human rights in accordance with international law' ${ }^{60}$ Article 6 states:

Response to disasters shall take place in accordance with the principles of humanity, neutrality and impartiality, and on the basis of non-discrimination, while taking into account the needs of the particularly vulnerable.

The Commentary to art. 6 notes that 'prohibited grounds for discrimination are non-exhaustive and include ethnic origin, sex, nationality, political opinion, race, religion and disability'. Although the grounds are described as non-exhaustive, it is notable that age is not explicitly listed. The Commentary also notes that the principle of non-discrimination does not prevent 'positive discrimination'. As for the reference to 'the particularly vulnerable', the ILC makes several points. First, the phrase is intended to encompass both vulnerable groups and vulnerable individuals. Fineman would approve the reference to individuals as well as groups, although the use of the phrase 'particularly vulnerable' can be traced to soft law sources including the 2007 Guidelines of the International Federation of Red Cross and Red Crescent Societies on international disaster relief and recovery assistance. ${ }^{61}$ Second, the qualifier 'particularly' was used in recognition of the fact that all those affected by disaster are by definition vulnerable. Third, the ILC decided against including a list of vulnerable groups within art. 6 in recognition of the relative nature of vulnerability - '[w] hat was important was less a fixed iteration of particularly vulnerable subgroups of individuals (...) and more a recognition that the principle of non-discrimination includes within it the positive obligation to give specific attention to the needs of the particularly vulnerable'. This approach reflects the human rights-based approach to non-discrimination which includes the need to pay attention to those who are vulnerable. The term 'particularly vulnerable' is therefore deliberately open-ended to include not only the categories of individuals usually associated with the concept, but also other possible individuals that might find themselves being particularly

\footnotetext{
6o Ibid., arts. 4-6.

61 O'Donnell (n 42) 580, citing 2007 Guidelines for the Domestic Facilitation and Regulation of International Disaster Relief and Initial Recovery Assistance.
} 
vulnerable in the wake of a disaster. In this sense, the Commentary chimes with Fineman's assertion that vulnerability is both universal and particular.

The reference to vulnerability in art 6 . is one of the 29 explicit references to the concept of vulnerability in the Draft Articles and their Commentaries. ${ }^{62}$ While this sounds promising, the Draft Articles have been critiqued as 'ultimately disappointing' as they fail to recognise the complexity of vulnerability. ${ }^{63}$ O'Donnell argues for a more socially constructed understanding of vulnerability, such as that reflected in Wisner's seminal work. As noted above, Wisner asserts that vulnerability means 'the characteristics of a person or group and their situation that influence their capacity to anticipate, cope with, resist and recover from the impact of a natural hazard. ${ }^{64}$ Like Fineman, O'Donnell argues that vulnerability is more than a mere label and is instead a 'social and political product' which reflects 'contemporary power imbalances' and so requires systemic analysis of structural inequalities. ${ }^{65}$ In contrast to this nuanced understanding, the ILC's notion of vulnerability appears predicated largely on the fact of exposure to disasters rather than recognising pre-existing vulnerabilities and associated state obligations. O'Donnell nevertheless mounts a strong argument that a structuralist approach to disaster vulnerability may enable a more creative reading of disaster reduction responsibilities of states and international cooperation. ${ }^{66}$

\subsection{Whither Vulnerability?}

Vulnerability is a complex concept whose parameters in international law have not been precisely pinned down. In international human rights law and practice, there is increasing invocation of the language of vulnerability by human rights bodies. Sometimes vulnerability is invoked intuitively, sometimes as an adjectival label, sometimes by reference to black-letter taxonomy and sometimes as a legal concept with associated obligations on states. There appears to be a growing understanding that vulnerability should lead to corresponding state obligations. Within human rights discourse, the principle of nondiscrimination, which encompasses protection for those who are vulnerable, is used to respond to the needs of vulnerable people, although the conceptual links between non-discrimination and vulnerability are not yet clear. Within international disaster law, the ILC's Draft Articles promisingly use the language

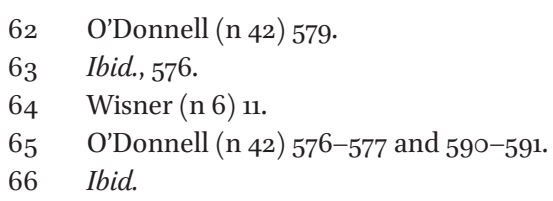


of vulnerability and recognise that individuals as well as groups may be vulnerable. However, the ILC's notion of vulnerability appears limited to the fact of exposure to disasters rather than recognising pre-existing vulnerabilities and associated state obligations. In sum, both international human rights law and international disaster law give some recognition to vulnerability, but there is room for development of more nuanced understandings.

This article now turns away from the theoretical to consider the practical experiences of older persons in New Zealand following the Canterbury earthquake series of 2010-2011. The intention is to use this national case study to explore the way in which vulnerability was utilised (or not) in relation to this particular group of people, and then to step back and reflect on these experiences in terms of vulnerability in the context of human rights and disaster law.

\section{The Experiences of Older Persons in Post-Quake Canterbury}

In light of the complexities of vulnerability, there are - unsurprisingly - disparities in the way the rights of different vulnerable groups are recognised in the disaster context. Bizzarri has suggested that '[c]ompared to other groups, older people suffer from a general neglect in both international laws and disaster policies and practices'.67 This is problematic given that the changing global demographic means that in future years, the number of older people worldwide who will be exposed to disasters will increase exponentially. ${ }^{68}$ It is partly for this reason that the experiences of older persons in post-quake Canterbury have been selected as a case study for this article. A second reason for selection of this group builds on the fallacies of mono-vulnerable groups discussed above as there were varying experiences of sub-groups and individuals within the group of older persons as well as varying experiences in different contexts. Finally, and partly in tribute, one of the vocal and effective grassroots advocacy groups in post-quake Canterbury was the Older Generations Forum, which strongly rejected paternalistic Government responses and eloquently and forcefully stated the concerns of older persons and sought to participate in decision making processes.

67 Bizzarri (n 9) 399 .

68 Jane Barratt, 'International Perspectives on Aging and Disasters', (2007) 31/4 Generations, 57,57 . 


\subsection{The 2010-2011 Canterbury Earthquakes}

On 4 September 2010 and 22 February 2011, the Canterbury region of New Zealand was hit by two large earthquakes. Although the September 2010 earthquake was bigger, the February 2011 earthquake caused more damage. The February 2011 earthquake was of 6.3 magnitude and resulted in the loss of 185 lives. Due to its shallow depth, its proximity to the city centre and peak ground acceleration, the damage to lives, property and livelihoods was extensive. ${ }^{69}$ The impacts of the 2010-2011 earthquake series continue to be felt even in 2020, with some people still facing difficult circumstances several years on. ${ }^{70}$

For the purposes of this article, "older persons" are defined as those aged 65 or over as this is the national (non-compulsory) retirement age in New Zealand. It is estimated that in 2010, 14.3 percent of the Canterbury population was aged 65 or over. ${ }^{71}$ Then, as now, the large majority of older persons in Canterbury lived independently in their own homes, with a smaller proportion in retirement villages or aged-care facilities.

For reasons of space, a comprehensive account of the experiences of older persons in post-quake Canterbury is not attempted; instead this part of the article presents three snapshots of issues affecting older persons - in the areas of evacuation, housing and resilience. Evacuation was selected because it was an issue that arose in the hours and days immediately following the February 2011 earthquake and involved the response of the health sector. In contrast, housing was selected given the protracted length of time for housing issues to be addressed and because it involved different sectors (housing and insurance). Resilience was considered given its linkages to the notion of vulnerability, and the overarching importance of resilience to disaster recovery. All three areas were the subject of intense popular, media and academic comment, concern and critique.

\subsection{Snapshot One: Evacuation}

A number of Christchurch rest homes and aged care facilities were severely impacted by the February 2011 earthquake. Nine residential care facilities were

69 For a summary of the impacts, see SH Potter, JS Becker, DM Johnston and KP Rossiter, 'An overview of the impacts of the 2010-2011 Canterbury earthquakes', (2015) 14 International Journal of Disaster Risk Reduction, 6.

70 Public Inquiry into the Earthquake Commission, 'What we heard: Summary of feedback from the Inquiry's public engagement' (March 2020), 1.

71 Joanne Allen, Lisa M Brown, Fiona M Alpass and Christine V Stephens, 'Longitudinal health and disaster impact in older New Zealand adults in the 2010-2011 Canterbury earthquake series', (2018) 61/7 Journal of Gerontological Social Work, 701, 702. 
closed and evacuated. ${ }^{72}$ In total, ${ }_{51} 6$ vulnerable elderly people were evacuated, representing the relocation of approximately ten per cent of the total number of older persons in subsidised residential care. ${ }^{73}$ Approximately 200 people were relocated within Canterbury, while 300 people were moved by plane or bus to aged-care facilities outside the region. The majority of evacuations took place within the first four days of the February earthquake. Journeys were lengthy (eight hours or more), and many evacuations took place over night.

One area of immediate concern was communication with the evacuees and their family members and caregivers at the time of the evacuation. Due to the emergency circumstances, evacuations had to take place quickly, and usual communication lines (telephone, email, cell phone networks) were compromised. There were also protocols which prevented leaving messages on answer phones for confidentiality reasons, and many contact details were incorrect or out of date. It was subsequently recommended that disaster planning should include education for older people and their caregivers about the possibility of emergency evacuations in the event of major disaster. ${ }^{74}$

Research conducted with evacuees and their caregivers identified that they were 'remarkably resilient' to their situation with resilience being promoted by personal attitudes, life experiences, and family and community support. ${ }^{75}$ The Government's Strategic Framework to support psychosocial recovery of the Canterbury population had identified 'the elderly who have been relocated to retirement homes outside Canterbury' as a particularly vulnerable group likely to have psychosocial needs and require support. ${ }^{76}$ This resulted in innovative provision of a travel subsidy for family members and caregivers which allowed them to visit and support the evacuees - a strategy that was widely praised. ${ }^{77}$ Aside from the initial communication challenges, and lessons learned for better transport management, the evacuation of rest home residents was regarded as largely successful and 'the right thing to do', with

72 Michael Ardagh and Joanne Deely, Rising from the Rubble: A health system's extraordinary response to the Canterbury earthquakes (Canterbury University Press 2018) 156.

73 Human Rights Commission, 'Monitoring Human Rights in the Canterbury Earthquake Recovery' (December 2013) 96.

74 Heppenstall at al 'Impacts of the Emergency Mass Evacuation of Elderly from Residential Care Facilities After the 2011 Christchurch Earthquake', (2013) 7/4 Disaster Medicine and Public Health Preparedness, 419, 422.

$75 \quad$ Ibid., 419 .

76 Ministry of Social Development, 'Strategic Planning Framework to support individual recovery and community wellbeing and to build community resilience following the 2010 Canterbury and 2011 Christchurch earthquakes' (May 2011) 14.

$77 \quad$ Heppenstall et al ( $\mathrm{n}_{74} 421$. 
300 people evacuated to a 'temporarily better life, and then most were brought back to their resurrected old one. ${ }^{78}$

\subsection{Snapshot Two: Housing}

One of the biggest challenges for many older people in the aftermath of the earthquakes was housing. Housing was widely impacted in Canterbury - in terms of the number of individuals affected, the challenges in protecting the right to housing, and the length of time taken to resolve housing issues. ${ }^{79} \mathrm{Of}$ the approximately 190,ooo dwellings in greater Christchurch, around 91 per cent were damaged by the earthquakes. Three issues were of particular concern to older people.

The first issue concerned the designation of certain parts of Christchurch as "residential red zone." Land so designated was either so badly damaged it was unlikely it could be reused for a prolonged period, or there were unacceptable risks to life and safety from rock fall or cliff collapse. At the same time as designating the residential red zone, the government offered to buy the properties in the residential red zone. One of the aims of this initiative was to provide certainty for homeowners and create confidence for people to move on with their lives. However, the amount of the government buy-out offer, compounded by the post-quake housing shortage meant that some people were not able to afford to purchase a new home. Many of those affected were older people who had been forced out of their long-term family home. ${ }^{80}$

The second, related issue concerned retirement villages in the residential red zone. The Government included four rest homes and retirement villages in its residential red zone buy-out offer. However, these payments went to the owners of the retirement villages, not the residents as they only had licences to occupy. Residents were left out of pocket and with insufficient funds to move into another retirement village. This was partly due to an administrative and regulatory oversight in the drafting of the Code of Practice governing retirement villages which had unintentionally excluded provision for no-fault termination of arrangement. ${ }^{81} \mathrm{~A}$ retirement village resident in another part of the country led a campaign to try and get a 'fair deal' for disadvantaged

78 Ardagh and Deely (n 72) 159 and 165.

79 For more detail on housing issues, see Natalie Baird, 'Housing in Post-quake Canterbury: Human Rights Fault Lines', (2017) 15 New Zealand Journal of Public and International Law, 195 .

8 I Ibid., 203 .

81 For discussion, see Alison Chamberlain, 'Unit Titles, Cross Leases and Retirement Villages' in Jeremy Finn and Elizabeth Toomey (eds), Legal Response to Natural Disasters (Thomson Reuters 2015) 323. 
residents. ${ }^{82}$ The Retirement Villages Association eventually made offers of assistance to all displaced residents including discounts on units, interest-free loans and fee waivers.

The third housing challenge for many older people was insurance. There was deep concern about the actions and omissions of both the Earthquake Commission (EQC) ${ }^{83}$ and private insurers. ${ }^{84}$ Concerns included unreasonable refusals to accept that losses were covered by insurance, delays in agreeing the quantum of claims, delays in paying out on accepted claims, and delays in repairing or rebuilding damaged properties. ${ }^{85}$ The power imbalance between EQC and insurers on the one hand and homeowners on the other was also a problem. These challenges affected almost every homeowner, but older people were especially vulnerable. Many older people were worried that their houses would not be rebuilt or repaired during their lifetimes - ' $\mathrm{u}]$ nfortunately time is the one thing that is not on us older folk's side. ${ }^{86}$

Both EQC and private insurers had criteria for identifying vulnerable homeowners, but there were persistent problems over a number of years with prioritisation of those who were vulnerable. EQC's initial criteria for vulnerable customers considered only health and age, although these were later broadened to consider factors such as dependency on a caregiver, terminal illness, ongoing medical condition or recent admission to hospital. ${ }^{87}$ Private insurers' criteria were typically wider and recognised not only age and health, but other factors such as disability and financial hardship. ${ }^{88}$ In response to concerns about poor prioritisation of repairs and rebuilds by both EQC and private insurers, the Human Rights Commission (HRC) eventually developed its own best practice guidelines for the prioritisation of vulnerable customers. ${ }^{89}$ The process for drafting the guidelines included a survey of public and private insurers on

82 "No success in battle for 'fair deal" (The Press, 5 August 2014).

83 The Earthquake Commission is the Crown entity that provides natural disaster insurance for residential properties under the Earthquake Commission Act 1993.

84 Baird (n 79) 207-209.

85 See Sarah Miles, The Christchurch Fiasco: The Insurance Aftershock and its Implications for New Zealand and Beyond (Dunmore Publishing 2012); and Jeremy Finn, 'Insurance Issues' in Jeremy Finn and Elizabeth Toomey (eds), Legal Response to Natural Disasters (Thomson Reuters 2015) 196.

86 John Patterson, 'Open letter to the Powers in Canterbury on behalf of our older generations' (Older Generations Forum, 13 November 2014).

87 Public Inquiry into the Earthquake Commission, 'Report of the Public Inquiry into the Earthquake Commission' (March 2020) 178.

88 HRC (n 73) 44.

89 Margaret MacDonald and Sally Carlton, 'Best practice guidelines for the prioritisation of vulnerable customers' (Human Rights Commission, 2016). 
dealing with vulnerable customers, engagement with the Insurance Council of New Zealand, and input from the New Zealand Red Cross and the Canterbury District Health Board. ${ }^{90}$ The HRC guidelines acknowledged the practical difficulties in identifying who is vulnerable, but also, interestingly, suggested that around eight per cent of insurance customers were likely to be vulnerable. ${ }^{91}$ The guidelines set out highly nuanced criteria for identifying vulnerability covering health and disability situation, living situation, family situation, age, geographic/environmental factors, non-English speaking household, the degree of support provided to others and the ability to understand insurance policies and processes. ${ }^{92}$

The 2020 Report of the Public Inquiry into EQC subsequently noted 'mixed views' from the public as to whether EQC's various attempts to identify and respond to vulnerable claimants had any tangible effect on their treatment. ${ }^{93}$ One major criticism was the delay in developing a set of nuanced vulnerability criteria, with most vulnerable customers only identified between August 2013 and May 2014. Other criticisms were the delay in establishing dedicated repair slots for those identified as vulnerable and that repairs for vulnerable people were not completed significantly faster than for other claimants. There was a strong sense from claimants that being classified as vulnerable made 'no difference' to the claim experience. ${ }^{94}$ It seemingly did not trigger any sense of corresponding obligation or action by EQC. The Inquiry recommended that EQC in future adopt a set of principles of practice including the principle of manaakitanga/respect - '[c]laimants are treated with dignity and courtesy, and care is shown for cultural values and vulnerable people. ${ }^{95}$ And, further, that EQC should '[d] evelop a policy for how it classifies claimants as vulnerable'. ${ }^{96}$

In March 202O, the UN Independent Expert on the enjoyment of all human rights by older persons visited New Zealand. ${ }^{97}$ At the time of writing, her report on the visit had not been released, but her public statements note that her initial assumptions about New Zealand as a positive place for older persons had proved incorrect. ${ }^{98}$ One area which she identified as particularly problematic

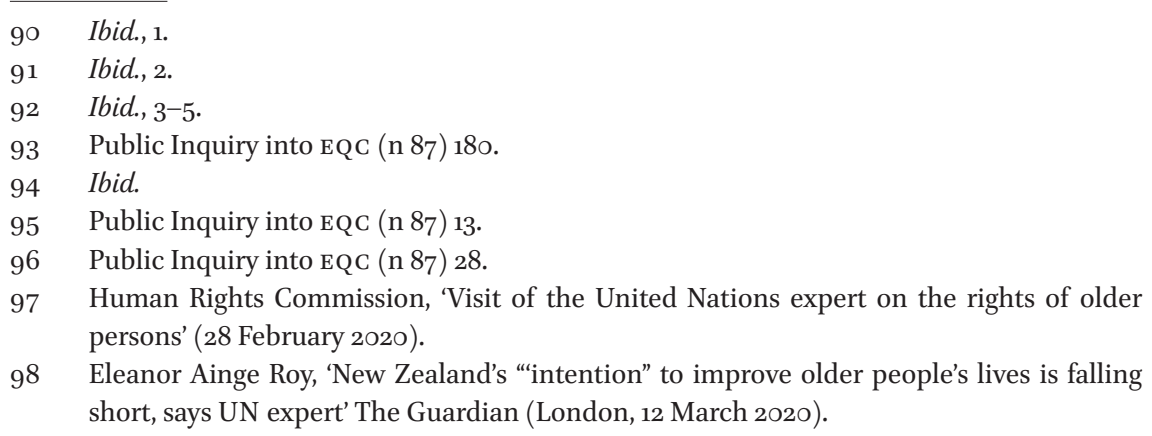


was inadequate housing. ${ }^{99}$ It is likely that a number of older persons living in inadequate housing in Christchurch can be linked to the failure to take full and proper account of their vulnerabilities following the 2010-2011 Canterbury earthquakes.

\subsection{Snapshot Three: Resilience}

Research at the global level suggests that in terms of psychosocial outcomes and mental health, some older adults display a high level of resilience following disasters. ${ }^{100}$ This conclusion was also reached in relation to older persons in Canterbury. A 2018 review of health and disaster impact on older persons in Canterbury concluded that there was little impact of the earthquakes on the health of surviving older persons, except in the case of those people with pre-disaster vulnerabilities; in that case, the earthquakes were associated with increased distress. ${ }^{101}$ Those in poor health reported a negative overall impact of the earthquakes compared to those in good health. Illustrating the compounding nature of vulnerability, it appears that 'a combination of poor physical and mental health, additionally characterized by older age, not being in paid employment, and poorer living standards, represent a risk profile for a more negative experience of distress and overall evaluation of the impact of events subsequent to the disaster.'102

Conversely, the Canterbury District Health Board has pointed out that obvious markers of vulnerability such as advanced age or physical or mental illness are not necessarily definitive. It further noted that some of those who were in fact vulnerable were not necessarily the expected constituency - 'some of those least able to manage after the Canterbury earthquakes were people, who, in normal times, were in control of and made decisions about their lives.' ${ }^{103}$ These observations illustrate the diversity of experience and dependencies, the need to guard against the essentialising risk of vulnerability, and the importance of considering the individual and not just the group to which they belong. A further example illustrating the risks in assuming vulnerability based on group membership alone is provided by the numerous instances of the "young-old" assisting the "old-old" to address their housing and other issues. ${ }^{104}$

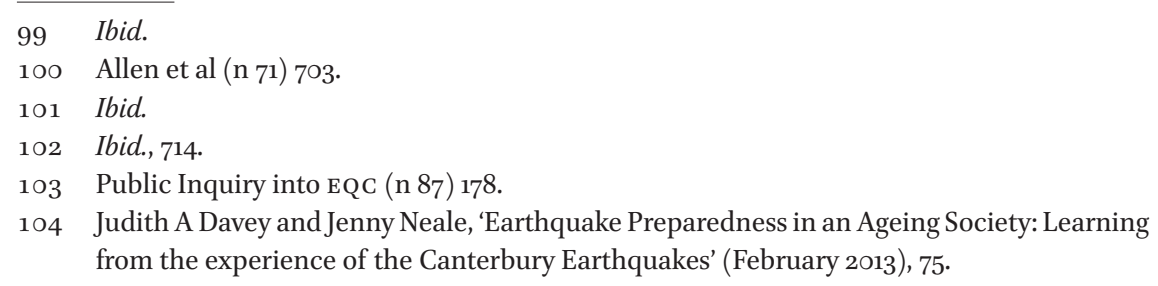


The Older Generations Forum, a grassroots group formed after the earthquakes to advocate for the needs and interests of older persons, firmly rejected the "vulnerable" label. Rather than being seen simply as passive recipients of care and attention, they sought to be involved as active participants and contributors to the recovery phase. Highlighting the negative connotations of vulnerability and the associated dangers of paternalism, a leader of the Older Generations Forum eloquently called for dispelling myths about older people:105

Younger people will be thinking 'those oldies at their forum will be having a good chat over a cup of tea but they needn't worry, we will look after them.' Look around this room. We have an ex-Mayor of Christchurch, an ex-Dean of the cathedral, an ex-Cabinet minister. We have ex-builders, plumbers, school teachers, nurses, engineers, accountants, etc. We have an enormous amount of skills, talents, expertise, experience, know-how and wisdom. It is high time that the powers that be and leaders of this city recognised this. They should be looking for ways to use this huge and growing resource.

\section{4}

\section{Reflections}

The experiences of older persons following the 2010-2011 Canterbury earthquake series reflect and confirm at a practical level much of the current conception of vulnerability within international human rights law and international disaster law. Five points are highlighted here. The first three points relate specifically to vulnerability, while the last two look more broadly at human rights-based approaches and potential areas for reform.

Based on the Canterbury experience, the first observation is that vulnerability is indeed complex - in both theory and practice. If it is to be more than an adjectival label, then vulnerability requires not just an understanding of its complexities, but corresponding action - at a minimum by state agencies but perhaps also other actors. The Canterbury experience illustrates this point with a notable contrast between the response of different actors. The local health sector appreciated the complexity of vulnerability and acted on it with targeted and tailored responses including the formation of a 'vulnerable persons team'. ${ }^{106}$ The insurance sector on the other hand initially failed to do

105 Ibid., citing John Patterson at the Older Generations Forum (April 2012).

106 Ardagh and Deely (n 72) 155 . 
much more than use vulnerability as a label. Both public and private insurers struggled to adequately identify exactly who was vulnerable. This resulted in various attempts by insurers and eventually the Human Rights Commission to produce vulnerability criteria. This engagement with vulnerability at a very practical level is remarkable in some ways and perhaps better than the position in many other jurisdictions. However, the 2020 recommendation that EQC develop a vulnerability policy shows that there is still work to be done to operationalise vulnerability.

The second observation is that vulnerability, like discrimination, is often compounding. While older persons as a group may have disproportionate negative outcomes following a disaster event, it is not age per se that gives rise to vulnerability but instead a combination of physiological, psychological, and socioeconomic factors. ${ }^{107}$ In particular, associations of high distress with poor health may reflect pre-earthquake vulnerabilities as opposed to the health impact of exposure to disaster. ${ }^{108}$ Similarly, in the insurance context, and this time viewing insurers in a slightly more positive light, EQC's guidelines for dealing with vulnerable claimants did evolve from initially considering only health and age to include a more complex range of factors. The Canterbury experience also showed that older people are not a monolithic group. The same factors can impact people differently, meaning that situations which negatively impact some people may not negatively impact others, and vice versa. ${ }^{109}$ Thus, many older people were remarkably resilient, while a smaller subset, often with some pre-existing health-related vulnerability, were less so. The 65-plus age group covers more than one generation and so there were many instances of the "young-old" assisting the "old-old". The compounding nature of vulnerability means that what is required, both in law and in practice, is the specific targeting of resources for particular subgroups of the older adult population. ${ }^{110}$ Disaggregated and granular data is required to 'allow for a differentiation of older and very old persons.'111 As with other population groupings, '[o]lder people are as diverse in their earthquake response as any age group, reminding everyone to look beyond the headlines and stereotypes.'112 Much like contemporary understandings of gender, age can also be a social construct.

\footnotetext{
107 Barratt (n 68) 58-59.

108 Allen et al (n 71) 715 .

109 MacDonald and Carlton (n 89) 2.

110 Allen et al (n 71) 714.

111 Independent Expert (n 43), para. 86.

112 Davey and Neale (n 104) 39.
} 
The third insight from Canterbury which reflects experience elsewhere is that 'sensitivity to diversity and inclusiveness continues to be mostly a theoretical commitment rather than a practice in disaster management'.113 In Canterbury in general, the Government's approach to recovery and reconstruction was very "top-down" rather than "bottom-up." This experience reflects international experience whereby 'vulnerable groups continue to be largely invisible, marginalised, and discriminated against in disaster management' with major inequalities between groups in terms of their inclusion and overall lack of a systematic approach. ${ }^{114}$

The 2002 Madrid Plan of Action on Ageing makes specific provision for 'emergency situations, such as natural disasters and other humanitarian emergencies' and recognises that 'older persons can make a positive contribution in coping with emergencies in promoting rehabilitation and reconstruction.'115 This Plan is nearly 20 years old, but perhaps due to its status as soft law, ${ }^{116}$ this exhortation has yet to be fully heeded. More recently and more generally, the Independent Expert on the enjoyment of all human rights by older persons has pointed out that what is still required is in fact a fundamental attitudinal shift - 'a re-conceptualizing of the way in which societies view older persons, from passive recipients of care and assistance to active contributors to society' 117 This attitudinal shift was perhaps eventually partly achieved in post-quake Canterbury after persistent advocacy by the Older Generations Forum and others for wider input from stakeholders into post-disaster recovery and reconstruction. The 2018-2020 Public Inquiry into the Earthquake Commission included a Community Reference Group comprised of a range of community leaders, advocates and $\mathrm{EQC} /$ insurance claimants with an understanding of peoples' experiences, and how people would want to engage and be informed. One of its members was the leading advocate of the Older Generations Forum. ${ }^{118}$

Broadening out beyond vulnerability per se, the fourth reflection is that just as international human rights law and practice does not yet comprehensively recognise the human rights dimensions of disasters, ${ }^{119}$ neither does domestic

\footnotetext{
113 Bizzarri (n 9) 409.

114 Ibid., 392.

115 Political Declaration and Madrid International Plan of Action on Ageing (2002), at paras. $54-56$.

116 Claudia Martin et al, Human Rights of Older People: Universal and Regional Legal Perspectives (Springer 2015) 350-351.

117 Independent Expert ( $\mathrm{n} 43$ ), para. 3.

118 Public Inquiry into EQC (n 87) 233.

119 Cubie and Hesselman ( $\mathrm{n}$ 57).
} 
human rights law and practice. Even though the New Zealand Human Rights Commission identified the earthquake series as 'one of New Zealand's greatest contemporary human rights challenges,',120 aside from the Commission itself, state agencies singularly failed to approach the aftermath of the earthquakes using a human rights lens, with human rights being virtually invisible in the Government's earthquake decision-making processes. ${ }^{121}$

However, despite this lack of human rights leadership or language, much of the response from the health sector did in practice reflect a human rightsbased approach - in substance, if not in name. For example, the recognition of the psychosocial needs and the importance of community supports to the rest home evacuees reflected a rights-based approach to disaster recovery planning. ${ }^{122}$ The health system's approach can be contrasted with the response of the insurance sector which mostly failed to take a human rights based approach. The success of the health system can be partly attributed to the 'collaborative and connected community of heath care providers' and the 'strong collegial relationships' within the health system that were already in place before the earthquakes. ${ }^{123}$ In addition, the health system response was based on local health board leadership (with central government support and facilitation). ${ }^{124}$ This meant there were close connections to the local community, and the ability to be more nimble and responsive. In contrast, EQC and insurance companies were more distant national entities, often underpinned by even more remote international reinsurers. In addition, the difference between the two sectors can perhaps be attributed to the fact that a public health system is well-attuned to making granular assessments of need on a regular basis whereas the insurance sector is not. Insurance also looks at statistical probabilities involving particular groups whereas a health system deals on a daily basis with considerable diversity amongst its constituency. The insurance sector also involved not only EQC (a public insurer) but also private insurance companies. The human rights obligations and responsibilities of companies is an evolving area, and while there were some positive developments in this area in Canterbury including a commitment by one insurer to 'respecting human rights in all client relationships', ${ }^{125}$ a comprehensive human rights-based approach was not evident.

\footnotetext{
$120 \operatorname{HRC}(\mathrm{n} 73) 7$.

121 Baird (n 79) 218-220.

$122 \operatorname{HRC}(\mathrm{n} 73) 96$.

123 Ardagh and Deely (n 72$) 11$.

124 Ibid., 272.

125 Baird (n 79) 217-218.
} 
The difference in responses between the health sector and the insurance sector illustrates that vulnerability may require different approaches in different sectors even within a single state. If vulnerability is to be a meaningful tool to achieve Fineman's goal of substantive equality, then development of a nuanced approach which takes account not only of the universal and the particular, but also of broader governance factors is required. Ultimately though, it is the state which is responsible for respecting, protecting and fulfilling individuals' human rights in the post-disaster context. The state therefore must undertake due diligence to ensure that its human rights obligations are met across the board and that this includes programmes and practices which respond to those who are especially vulnerable.

The final reflection from the experience of older people in post-quake Canterbury is that it illustrates two areas where development of the international legal framework is desirable. Older people are not currently as well-protected within the international legal framework as other groups. Foundational human rights instruments such as the UDHR, the ICCPR and the ICESCR do not specifically recognise age as a prohibited ground of discrimination, although age would be captured under the "or other status" ground. In addition, unlike women, children, people with disabilities, refugees, stateless persons, and migrant workers, there is not yet an international treaty on the rights of older persons. There is currently one in development, although it still appears some time away from fruition. ${ }^{26}$ The eventual treaty should make specific provision for the human rights of older persons in the context of disasters including the need for recognition and protection of especially vulnerable older persons, and the importance of the participation of older persons in disaster preparedness, prevention, reconstruction and recovery activities. Precedents can be found in art. 11 of the CRPD, art. 14 of the Protocol to the African Charter on Human and Peoples' Rights on the Right of Older Persons and art. 29 of the Inter-American Convention on Protecting the Human Rights of Older Persons. ${ }^{127}$ Adoption of a treaty on the rights of older persons would

126 For a summary of international developments, see HR Council, 'Activities of the Office of the United Nations High Commissioner for Human Rights, the United Nations system and regional organizations to support States' efforts to promote and protect the human rights of older persons: Report of the Office of the United Nations High Commissioner for Human Rights' (21 June 2019) A/HRC/41/32.

127 Article 11 CRPD requires states to take 'all necessary measures to ensure the protection and safety of persons with disabilities in situations of risk, including situations of armed conflict, humanitarian emergencies and the occurrence of natural disasters'. Article 14 of the African Protocol provides that states shall 'ensure that, in situations of risk, including natural calamities, conflict situations, during civil strife or wars, Older Persons shall be among those to enjoy access, on a priority basis, to assistance during rescue efforts, 
do much to embed older people as a distinct group both within international human rights law, and in other areas such as international disaster law. Ideally the treaty would explicitly reference vulnerability, and recognise the diversity of the constituency of older persons, but even if it merely enabled the recognition of vulnerability under its umbrella, then in conjunction with a specific article on disasters, this would provide a firm footing for future development.

The second area where development of the international legal framework is desirable is in relation to business and human rights. As noted above, private insurance companies had a significant impact on the right to housing of many older persons in Canterbury, and they particularly struggled with how to recognise vulnerability in prioritisation of claims. In recent years, there has been growing recognition of the negative (and positive) impacts that businesses can potentially have on the realisation of human rights. In 2011, the United Nations adopted the UN Guiding Principles on Business and Human Rights. ${ }^{128}$ As with the rights of older persons, preparatory work is under way on a draft business and human rights treaty. ${ }^{129}$ It remains to be seen whether a treaty in this area can be successfully concluded, but, it too, could usefully include provisions on both vulnerability and disasters.

settlement, repatriation and other interventions; and ensure that Older Persons receive humane treatment, protection and respect at all times and are not left without needed medical assistance and care'. Article 29 of the Inter-American Convention provides: 'States Parties shall adopt all necessary specific measures to ensure the safety and rights of older persons in situations of risk, including situations of armed conflict, humanitarian emergencies, and disasters, in accordance with the norms of international law, particularly international human rights law and international humanitarian law. States Parties shall adopt assistance measures specific to the needs of older persons in preparedness, prevention, reconstruction, and recovery activities associated with emergencies, disasters, and conflict situations. States Parties shall foster the participation of interested older persons in civil protection protocols in the event of natural disasters'.

128 HR Council, 'Guiding Principles on Business and Human Rights: Implementing the UN "Protect, Respect and Remedy" Framework' (21 March 2011) A/HRC/17/31.

129 HR Council, 'Report on the fourth session of the open-ended intergovernmental working group on transnational corporations and other business enterprises with respect to human rights' (2 January 2O19) A/HRC/40/48. 
This article set out to consider the linkages between vulnerability, international human rights and international disaster law. Drawing on the experience of older persons in post-quake Canterbury, the aim was to reflect on the way in which the concept of vulnerability was used (or not) in relation to older people in Canterbury, and consider any insights for development of the concept in international human rights and international disaster law and practice. The overall conclusion is that, despite its complexities and uncertainties, vulnerability is a useful concept for considering the rights of particular individuals and groups in the disaster context.

In essence, if people are vulnerable, they are, for a multiplicity of individual and structural reasons, less able than others to cope with and recover from a disaster. In order for the notion of vulnerability to make a positive difference, it needs to be more than a simple adjectival label. Vulnerability can be intersectional and compounding - it does not belong to any one particular group but can arise from the interrelationship of many factors. It can be used to promote substantive equality, and it should result in clear obligations on state, and perhaps even non-state, actors. It also needs to be viewed as both universal and particular - everyone is susceptible to vulnerability, not just members of typically vulnerable groups. Although the precise parameters of vulnerability remain uncertain, within both international human rights and international disaster law and practice, and their domestic equivalents, there are promising signs that vulnerability is increasingly recognised and utilised as something more than a mere label.

The case study showed some usage of the vulnerability concept in relation to older peoples' experiences after the Canterbury earthquake series of 20102011. It illustrated the complexities of vulnerability, its compounding nature and the need for caution to avoid paternalistic responses and stigmatisation of those deemed vulnerable. One interesting insight was the contrast between the health and insurance sectors, with the health sector responding reasonably well to the vulnerability of older persons, and the insurance sector significantly less so - suggesting the importance of context and experience in operationalising vulnerability in practice. A second insight was recognising the impact that non-state actors may have on the rights of vulnerable individuals and groups in the post-disaster context. The Canterbury case study also illustrated that the adoption of two international treaties currently under development would help to promote the rights of vulnerable older persons in disasters - a treaty on the rights of older persons, and a treaty on business and human rights. 
Despite the ambiguities inherent in the concept of vulnerability, its partial and piecemeal application in international human rights law and disaster law, and its mixed utility in a national crisis context, the concept does offer scope to better protect the rights of the most vulnerable in a post-disaster setting. Or, as Fineman says, vulnerability analysis offers the opportunity to explore 'the human part, rather than the rights part, of the human rights trope. ${ }^{130}$ If this can be done successfully, then vulnerability has much to offer international disaster law and practice.

130 Fineman (n 8) 255 . 